\title{
IDENTIFICAÇÃO E PROIBIÇÃO DO BULLYING ESCOLAR NO ORDENAMENTO JURÍDICO BRASILEIRO: PERSPECTIVA DE VIOLAÇÃO DOS DIREITOS HUMANOS DE CRIANÇAS E ADOLESCENTES
}

\author{
IDENTIFICATION AND PROHIBITION OF \\ SCHOOL BULLYING IN BRAZILIAN LAW: \\ PERSPECTIVE OF VIOLATION OF HUMAN \\ RIGHTS OF CHILDREN AND TEENAGERS
}

Jailton Macena Araujo * Elma Moreira de Assis ${ }^{* *}$

\section{RESUMO}

O termo bullying diz respeito às ações que tiranizam, ameaçam, oprimem, amedrontam e intimidam, consistindo em uma forma de agressão física e/ou moral contra determinada pessoa ou grupo minoritário. É caracterizado pelo caráter sistemático, repetitivo e violador que possui. Identificar os agentes dessa forma de violência não é tarefa fácil, porque muitas vezes a vítima permanece calada em face das agressões sofridas. Provavelmente, o fenômeno bullying sempre existiu, entretanto apenas atualmente, ele tem sido identificado e discutido em vários países do mundo. O objetivo deste estudo foi analisar o modo de exteriorização do bullying, principalmente no ambiente escolar, e sua consequência no

\footnotetext{
Mestre em Ciências Jurídicas pela Universidade Federal da Paraíba (2011), aprovado “com distinção"; especialista em Direito Processual pela Universidade Anhanguera - Uniderp (2010); graduado em Direito pela Universidade Federal de Campina Grande (2007); professor da Universidade Federal de Campina Grande; advogado. Contato: jailtonma@gmail.com

* Graduada em Direito pela Universidade Federal de Campina Grande (UFCG). Contato: elma_moreira@hotmail.com
} 
mundo jurídico. A questão central em que se pautou este trabalho foi o estudo sobre o bullying e suas formas de manifestação, enfatizando o tratamento jurídico conferido ao tema, bem como identificando qual seria o seu enquadramento legal mais justo e sua punição. Utilizando como procedimento metodológico a pesquisa bibliográfica, procurou-se identificar o problema do bullying na sociedade moderna, enfatizando suas formas e consequências, bem como analisando a proibição do bullying no ordenamento jurídico brasileiro, atentando para as previsões legais que combatem sua prática e a responsabilidade jurídica que advém para os autores dessa forma de violência.

Palavras-chave: Bullying. Responsabilidade. Estatuto da Criança e do Adolescente.

\begin{abstract}
The expression bullying refers to the actions which tyrannize, threaten, oppress, frighten and intimidate, consisting in a form of aggressive behavior physical and/or moral against a person or a minority group, which is characterized by the systematic, repetitive and violating character. Identify the bullies is not easy, due to the fact that most of the time, the victims do not talk about the abuse that they have been through. The phenomenon of bullying has always been around, however just recently, it has been recognized and discussed in several countries around the world. The aim of this study was analyze the way of externalization of bullying, especially on schools, and also its consequences on the legal system. The main focus of this work is the study of bullying and its ways of manifestation, emphasizing the role of the legal system in tackling this issue, with the aim of identify the correct criminal definition and the best way of punishment for perpetrators. The methodological procedures for this work, was based on bibliographic research. The aim is to identify the problem of bullying in modern society, emphasizing their ways and consequences, also consider anti-bullying legislation in the Brazilian legal system, paying attention to legal provisions to fight against this practice and the legal liability that may occurs to the perpetrators of this kind of violence.
\end{abstract}

Keywords: Bullying. Responsability. Statute of Children and Adolescents. 


\section{INTRODUÇÃO}

O bullying, termo em inglês popularizado em nosso país, é um fenômeno que atormenta diariamente milhões de pessoas, sobretudo crianças e adolescentes. Trata-se de uma forma de violência injustificada e contínua, praticada por um indivíduo ou grupo minoritário contra alguém integrante de sua relação de convívio, com o fim de atacar a estrutura física e/ou psíquica das vítimas, mediante a prática de atos que envolvem tortura, desprezo, intimidação, entre outros.

O bullying é caracterizado pelo caráter sistemático, repetitivo e violador que possui, não se referindo à simples brincadeiras inerentes à infância, como querem apontar os céticos da existência desse fenômeno, que atribuem sua incidência ao sensacionalismo da mídia, professores, ou psicólogos, entre outros. Ao contrário, consiste em uma forma de violência física e/ou moral, em vários casos por meio de intimidações veladas praticadas pelos agressores.

Não é simples identificar os agentes dessa forma de violência. Isso ocorre porque muitas vezes a vítima, por não encontrar coragem para se defender, permanece calada em face das agressões sofridas, o que acaba encobrindo e dificultando a identificação e repressão dos agressores.

Embora seja registrado noutros espaços, o bullying praticado no ambiente escolar é a forma mais comum de violência, e a mais veiculada nos meios de comunicação. Isso se dá, principalmente, porque a escola é o local onde se convive com a diversidade humana e nela existem indivíduos com diferentes comportamentos.

Não se refere a uma forma qualquer de violência, diz respeito ao isolamento intencional, aos apelidos vexatórios, às gozações que magoam e constrangem, entre outras.

O enfoque do presente trabalho, portanto, é a análise sobre o modo de exteriorização do bullying no ambiente escolar e sua consequência no mundo jurídico. 


\section{BULLYING: BREVES APONTAMENTOS E CON- CEITUAÇÃO}

O bullying é um fenômeno que certamente sempre existiu. É uma prática que cresce a cada dia, de forma silenciosa e assustadora, e consiste em uma forma de agressão física e/ ou moral contra determinada pessoa ou grupo minoritário, caracterizado pelo caráter sistemático, repetitivo e violador que possui.

Esse fenômeno só passou a ser investigado na década de 70 quando, devido ao alto índice de suicídios que ocorreram com crianças e adolescentes naquela época, o pesquisador norueguês Dan Olweus, então professor na Universidade de Bergen, desenvolveu uma pesquisa com alunos em escolas públicas e particulares acerca do motivo desses suicídios, concluindo que muitos eram vítimas de violência e agressões repetitivas por parte dos colegas, fato que gerava sentimentos negativos, pessimistas e de frustração, enfim tão destrutivos que chegavam ao ponto de levá-los a ceifar a própria vida. ${ }^{1}$

Fante e Pedra, ${ }^{2}$ grandes precursores dos estudos desse fenômeno no âmbito nacional, contribuem para se entender que:

Bully pode ser traduzido como valentão, tirano, brigão. Como verbo, bully, significa tiranizar, amedrontar, brutalizar, oprimir, e o substantivo bullying descreve o conjunto de atos de violência física ou psicológica, intencionais e repetidos, praticados por um indivíduo (bully) ou grupo de indivíduos com o objetivo de intimidar ou agredir outro indivíduo (ou grupo de indivíduos) incapaz de se defender [...]. O abuso de poder, a intimidação, a prepotência, são algumas das estratégias que o bully adota para impor sua autoridade e manter suas vítimas sob domínio [...]. Os bullies estão em toda parte [...] nos mais diversos contextos sociais.

Desse modo, o bullying, termo em inglês popularizado em nosso país, pode ser adotado para abarcar todo tipo de comportamento agressivo, compreendendo atos de violência injustificada e contínua no campo das relações interpessoais.

Conforme assevera Middelton-Moz: ${ }^{3}$ 
Os comportamentos incluídos no bullying são vários: ofender, humilhar, espalhar boatos, fofocar, expor ao ridículo em público, fazer de bode expiatório e acusar, isolar, designar áreas de trabalho ou tarefas ruins ou negar férias e feriados no local de trabalho, dar socos, tapas, chutes, insultar, ostracizar, sexualizar ou fazer ofensas étnicas ou de gêneros.

Nesse diapasão, como forma de especificar os atos caracterizadores da incidência dessa prática, o próprio pesquisador Dan Olweus estabeleceu alguns critérios básicos para identificar as condutas de bullying e diferenciá-las de outras formas de violência e das brincadeiras próprias da idade. Os critérios estabelecidos são: ações repetitivas contra a mesma vítima num período prolongado; desequilíbrio de poder, o que dificulta a defesa da vítima; bem como ausência de motivos que justifiquem os ataques. ${ }^{4}$

Assim, analisando esse padrão característico, procura-se compreender essa faceta da violência, desmascarando seus participantes a fim de evitar que essa prática se espalhe para outros campos do convívio humano ou vitime mais indivíduos.

\section{PARTICIPANTES DO BULLYING}

Identificar os agentes dessa forma de violência não é tarefa fácil. Isso se dá porque muitas vezes a vítima, por não encontrar coragem para se defender, permanece calada em face das agressões sofridas, $\mathrm{o}$ que acaba encobrindo e dificultando a identificação e repressão dos agressores.

Atua como agressor aquele indivíduo que vitimiza os mais frágeis, normalmente se apresentando mais forte que seus companheiros de classe e que suas propensas vítimas. Geralmente é membro de uma família desestruturada, na qual o relacionamento afetivo é deficitário, tendo pais que usam meios violentos como forma de solucionar conflitos. São considerados malvados, apresentando dificuldades para adaptar-se às normas, adotando condutas antissociais e sentindo-se atraído pelas más companhias. ${ }^{5}$

São os chamados bullies, pessoas que gostam de exercer poder e controle sobre uma ou mais vítimas, eleitas para sofrerem agressões de 
forma aleatória, talvez por apresentarem aparência física característica, ou por serem mais reservadas. Na maioria das vezes, os ofendidos são aqueles taxados como "esquisitos", que se mostram tímidos, retraídos, passivos, submissos, ansiosos, temerosos, com dificuldades de defesa, de expressão e de relacionamento. Além desses, outros fatores também influenciam, como: as diferenças de raça, credo, opção sexual, sotaque, maneira de se vestir, entre outros. O perfil das vítimas de bullying é o mesmo em outros ambientes, como no trabalho, por exemplo. ${ }^{6}$

Além dessa figura típica de vítima, surge nesse cenário a vítima provocadora, aquela que instiga reações agressivas contra si mesma, porém não consegue se defender dos revides. São geralmente aquelas crianças ou adolescentes hiperativos e impulsivos e/ ou imaturos, que acabam por criar um ambiente tenso na escola. Eles fazem com que a atenção dos espectadores se volte para si, o que acaba por mascarar a ação dos verdadeiros agressores. ${ }^{7}$

Não obstante, pode entrar em cena a chamada vítima agressora, aquela que reproduz os maus-tratos sofridos como forma de compensação, isto é, procura outra vítima ainda mais frágil e vulnerável e comete contra esta todas as agressões que sofreu. Esse caso dificulta mais ainda o controle do bullying, acionando um efeito "cascata" ou de círculo vicioso, em que a figura de seus agentes se confunde ainda mais, uma vez que uma mesma pessoa atua ora como vítima, ora como agressora. ${ }^{8}$

Por sua vez, os espectadores dessa forma de violência não costumam apresentar em seu comportamento sinais explícitos que denunciem a situação que estão vivendo ou participando. Os passivos são tendenciosos a se manterem calados sobre o que sabem ou presenciam, por medo absoluto de se tornarem a próxima vítima. Em contrapartida, os espectadores ativos são aqueles que participam indiretamente dos ataques, dando "apoio moral" aos agressores, incentivando com risadas, palavras ou gestos que incentivam a violência. Os neutros, por fim, demonstram indiferença às situações de bullying que observam, como se fossem acometidos por uma "anestesia emocional", advinda do próprio contexto social no qual estão inseridos, provavelmente originários de lares desestruturados ou de comunidades em que a violência é rotineira. ${ }^{9}$ 
Portanto, o grande desafio em identificar os sujeitos que estão inseridos nesse triste cenário de violência - bullying - consiste em identificar os agressores que podem ser recuperados, por meio de ações e estratégias escolares ou sociais, daqueles que apresentam traços violentos natos, mostrando total indiferença ao sofrimento alheio. Nesse caso, a diferenciação se mostra crucial para retirar muitos desses jovens dessa realidade de violência e, muitas vezes, transformá-los em defensores da paz, sendo verdadeiro exemplo para os demais.

\section{BULLYING ESCOLAR}

O bullying praticado no ambiente escolar é a forma mais comum de violência e a mais veiculada nos meios de comunicação. Nesse sentido, Abramovay e Calaf ${ }^{10}$ esclarecem:

[...] o bullying sempre existiu, especialmente por meio de relações conflituosas entre alunos. Muitas vezes, essas atitudes passam despercebidas pelos adultos das escolas, já que são consideradas rotineiras e, portanto, não avocam sua atenção [...]. As relações sociais entre os diversos atores presentes no ambiente escolar são produtoras de violências de várias espécies, como agressões físicas, agressões verbais, ameaças, furtos, discriminações racistas e sexistas, e violência sexual. Em outras palavras a escola é um território de produção de violências das mais diversas ordens, tipos e escalas.

Não se refere a uma forma qualquer de violência; diz respeito ao isolamento intencional, aos apelidos vexatórios, às gozações que magoam e constrangem etc. De maneira oportuna, Fante ${ }^{11}$ acrescenta:

Essa forma de violência gratuita ocorre na relação entre pares, sendo sua incidência maior entre os estudantes, no espaço escolar. Caracteriza-se pela intencionalidade e continuidade de ações agressivas contra a mesma vítima, sem motivos evidentes, resultando danos e sofrimentos, e dentro de uma relação desigual de poder, o que possibilita a vitimação.

Portanto, é imprescindível que pais e educadores estejam atentos a essa prática nociva ao ambiente escolar, aplicando ações e estratégias a fim de prevenir e reprimir sua incidência, como forma de evitar os efeitos danosos sofridos pelas vítimas. 


\section{O PAPEL DA ESCOLA NO COMBATE AO BULLYING}

A escola é o espaço principal de formação de cidadãos e de exercício da cidadania plena, opondo-se a processos de negação dessa perspectiva. É o local fundamental da formação humana, de construção de sua dignidade, por isso contrapõe-se a ações que caminhem na contramão desse processo, como as práticas de bullying.

Não obstante, esse ambiente, que deveria funcionar como uma extensão da casa dos estudantes, tem sido o palco principal da ação dos bullies, mediante o uso de práticas de violência que agridem essencialmente a dignidade humana.

Lopes Neto ${ }^{12}$ esclarece:

O termo violência escolar diz respeito a todos os comportamentos agressivos e anti-sociais, incluindo os conflitos interpessoais, danos ao patrimônio, atos criminosos, etc. Muitas dessas situações dependem de fatores externos, cujas intervenções podem estar além da competência e capacidade das entidades de ensino e de seus funcionários. Porém, para um sem número delas, a solução possível pode ser obtida no próprio ambiente escolar.

Ora, acontece que a maioria das escolas ainda não está preparada para identificar e enfrentar a violência entre seus alunos, ou entre esses alunos e o corpo acadêmico, devido, em parte, ao desconhecimento, omissão e/ou negação desse fenômeno.

Assim a Revista Construir Notícias ${ }^{13}$ faz o seguinte alerta:

Apesar da profusão de informações, a temática ainda está distante da maioria dos profissionais que atuam na área educacional e, quando estes declaram ter alguma informação sobre o assunto, na maioria das vezes ela está ligada a algum relato que presenciou ou ouviu falar, não havendo maior aprofundamento. No que tange a alunos e pais, as informações são mais superficiais ainda, revelando que o fenômeno bullying - apesar de estar presente na grande maioria das escolas brasileiras, das redes pública e particular e atingir alunos de diferentes níveis de ensino, da Educação Infantil ao EnsinoSuperior, com consequência para o desenvolvimento e a aprendizagem do educando - é desconhecido da comunidade escolar. 
Dessa feita, para inverter essa realidade, os profissionais da educação precisam inicialmente reconhecer a existência do bullying, em todas as suas variações, e tomar consciência das consequências danosas que ele pode trazer para o desenvolvimento dos estudantes.

Esses profissionais precisam ser capacitados para saber lidar com esse fenômeno, sendo capazes de identificar, diagnosticar e cuidar dos casos de bullying que presenciem ou vivenciem, agindo tanto de forma preventiva quanto repressiva. ${ }^{14}$

As escolas devem cumprir seu papel social, atuando não só no sentido de conferir aprendizado do conteúdo programático ao aluno, mas conferindo-lhe valores, formando verdadeiros cidadãos.

Entretanto, o bullying já assumiu uma dimensão tão ampla que a escola sozinha não é capaz de resolvê-lo. Ela necessita do auxílio de toda a comunidade, incluindo pais, alunos e outros profissionais, como pedagogos ou psicólogos. Assim, Lopes Neto ${ }^{15}$ obtempera:

O envolvimento de professores, funcionários, pais e alunos é fundamental para a implementação de projetos de redução do bullying. A participação de todos visa estabelecer normas, diretrizes e ações coerentes. As ações devem priorizar a conscientização geral; o apoio às vítimas de bullying, fazendo com que se sintam protegidas; a conscientização dos agressores sobre a incorreção de seus atos e a garantia de um ambiente escolar sadio e seguro [...]. Deve-se encorajar os alunos a participarem ativamente da supervisão e intervenção dos atos de bullying, pois o enfrentamento da situação pelas testemunhas demonstra aos autores que eles não terão o apoio do grupo.

Ademais, Fante ${ }^{16}$ complementa:

Enfrentar a violência não é tarefa fácil. A violência é um fenômeno social, complexo, multifatorial. A escola sozinha não consegue conter as violências sem a participação, envolvimento e compromisso da família, sem o apoio de instituições que asseguram os direitos de crianças e adolescentes, sem o comprometimento efetivo de governos na criação de políticas públicas e investimentos em projetos concretos - que ofereçam oportunidades de mudanças significativas da vida de crianças e adolescentes - capacitação de profissionais de educação, saúde, assistência social, operadores do direito, dentre outros, para o desenvolvimento de programas preventivos eficazes. 
Portanto, a escola pode e deve procurar resolver o problema dentro de seus limites físicos, por meio de uma ação multidisciplinar na qual devem estar envolvidos, além de vítima e agressor, os pais de ambos e toda a comunidade.

No entanto, se houver a ocorrência de casos mais graves, deve recorrer ao auxílio da autoridade policial ou do Ministério Público, visto que o bullying é proibido no ordenamento jurídico brasileiro.

\section{PROIBIÇÃO DO BULLYING NO ORDENAMENTO JURÍDICO BRASILEIRO}

O Brasil contemplou a preservação da dignidade da pessoa humana no art. $1^{\circ}$ da Constituição Federal de 1988, constituindo-se um dos fundamentos do Estado Democrático de Direito. A Carta Magna em vigor assegura ao ser humano direitos básicos e fundamentais, objetivando que o cidadão tenha condições de sobreviver e com uma vida digna.

Ao falar em condições dignas para se viver, está se referindo à oportunidade de viver em condições satisfatórias, em paz e com qualidade. Nesse sentido, as práticas de bullying violam frontalmente os direitos fundamentais previstos no art. $5^{\circ}$ da Lei Maior, que assim expressa in verbis:

Art. $5^{\circ}$. Todos são iguais perante a lei, sem distinção de qualquer natureza, garantindo-se aos brasileiros e aos estrangeiros residentes no País a inviolabilidade do direito à vida, à liberdade, à igualdade, à segurança e à propriedade, nos termos seguintes:

[...]

II - Ninguém será obrigado a fazer ou deixar de fazer alguma coisa senão em virtude de lei;

III - ninguém será submetido à tortura nem a tratamento desumano ou degradante;

$[\ldots]$

X - são invioláveis a intimidade, a vida privada, a honra e a imagem das pessoas, assegurado o direito à indenização pelo dano material ou moral decorrente de sua violação;

$[\ldots]$ 
XV- é livre a locomoção no território nacional em tempo de paz, podendo qualquer pessoa, nos termos da lei, nele entrar, permanecer ou dele sair com seus bens;

$[\ldots]$

XX - ninguém poderá ser compelido a associar-se ou a permanecer associado;

\section{$[\ldots]$}

XLI - a lei punirá qualquer discriminação atentatória dos direitos e liberdades fundamentais;

XLII - a prática do racismo constitui crime inafiançável e imprescritível, sujeito à pena de reclusão, nos termos da lei;

XLIII - a lei considerará crimes inafiançáveis e insuscetíveis de graça ou anistia a prática da tortura, o tráfico ilícito de entorpecentes e drogas afins, o terrorismo e os definidos como crimes hediondos, por eles respondendo os mandantes, os executores e os que, podendo evitá-los, se omitirem ${ }^{17}$ (BRASIL, 2009, p. 15-17).

À luz dos princípios constitucionais supramencionados, pode-se concluir que o ordenamento jurídico pátrio preserva a dignidade da pessoa humana. O legislador constituinte instituiu os chamados direitos e garantias fundamentais, dando relevância jurídica ao princípio universal da dignidade humana, por meio da proteção à vida, à saúde e integridade física e psíquica, à liberdade, à igualdade, à intimidade e privacidade, ao trabalho, à educação, à propriedade, enfim, objetivou proteger aquilo que é essencial para a consecução de uma vida digna.

Nesse sentido, Bastos, ${ }^{18}$ ao tratar da dignidade humana assevera:

[...] Embora tenha um conteúdo moral, parece que a preocupação do legislador constituinte foi mais de ordem material, ou seja, a de proporcionar às pessoas condições para uma vida digna [...]. Este foi, sem dúvida, um acerto do constituinte, pois coloca a pessoa humana como fim último de nossa sociedade e não como simples meio para alcançar certos objetivos, como, por exemplo, o econômico.

Depreende-se, portanto, que a dignidade humana é considerada como valor supremo e fundamento primário de todo ordenamento 
jurídico brasileiro, sendo princípio basilar a ser pontuado em toda e qualquer relação humana, pois implica o dever de respeito e consideração mútuo.

A par das considerações esposadas, tem-se que o bullying praticado no ambiente escolar, seja do professor em relação ao aluno, seja do aluno em relação ao professor, constitui-se em flagrante atentado à dignidade humana, pois compreende atos de violência que atentam contra a liberdade, integridade psíquica e física, intimidade e privacidade, enfim, ferem atributos inerentes a toda pessoa vitimada, implicando violação aos direitos e garantias fundamentais protegidos pela Constituição Federal. ${ }^{19}$

Saliente-se, portanto, que a dignidade humana não é mensurável ou substituível, sendo atributo intrínseco e absoluto, inerente a qualquer indivíduo. Apresenta-se como elementar à constituição de um mínimo de vida digna, proporcionando o desenvolvimento humano e possibilitando a convivência em sociedade.

Ademais, a referida Constituição Federal de 1988 consagrou, em seu art. 227, o princípio da prioridade absoluta, determinando os direitos que devem ser assegurados a crianças e adolescentes:

É dever da família, da sociedade e do Estado assegurar à criança e ao adolescente, com absoluta prioridade, o direito à vida, à saúde, à alimentação, à educação, ao lazer, à profissionalização, à cultura, à dignidade, ao respeito, à liberdade e à convivência familiar e comunitária, além de colocá-los a salvo de toda forma de negligência, discriminação, exploração, violência, crueldade e opressão.

$\S 1^{\circ} \mathrm{O}$ Estado promoverá programas de assistência integral à saúde da criança e do adolescente, admitida a participação de entidades não-governamentais [...];

\section{[...]}

$\S 3^{\circ} \mathrm{O}$ direito a proteção especial abrangerá os seguintes aspectos:

I - idade mínima de quatorze anos para admissão ao trabalho, observado o disposto no artigo $7^{\circ}$, XXXIII;

II - garantia de direitos previdenciários e trabalhistas;

III - garantia de acesso do trabalhador adolescente à escola; 
IV - garantia de pleno e formal conhecimento da atribuição de ato infracional, igualdade na relação processual e defesa técnica por profissional habilitado, segundo dispuser a legislação tutelar específica;

V - obediência aos princípios de brevidade, excepcionalidade e respeito à condição peculiar de pessoa em desenvolvimento, quando da aplicação de qualquer medida privativa da liberdade;

VI - estímulo do Poder Público, através de assistência jurídica, incentivos fiscais e subsídios, nos termos da lei, ao acolhimento, sob a forma de guarda, de criança ou adolescente órfão ou abandonado;

VII - programas de prevenção e atendimento especializado à criança e ao adolescente dependente de entorpecentes e drogas afins. ${ }^{20}$

Destarte, nenhum outro grupo social recebeu proteção tão abrangente pela família, pela sociedade ou pelo Estado. Segundo Ferreira, ${ }^{21}$ "[...] crianças e adolescentes ganham um novo 'status', como sujeitos de direitos e não mais como menores objetos de compaixão e repressão, em situação irregular, abandonadas ou delinqüentes".

A Constituição de 1988 inovou doutrinariamente ao elevar as crianças e os adolescentes ao patamar de sujeitos jurídicos, declarando-lhes proteção especial e prioridade imediata e absoluta na busca da eficácia plena do direito dos quais eles passaram a ser titulares. ${ }^{22}$

Portanto, em frente às discussões em torno do bullying, sua prática contra crianças ou adolescentes fere o preceito constitucional da prioridade absoluta, visto que o legislador constituinte teve a preocupação de assegurar e priorizar direitos fundamentais àquele grupo social, objetivando seu pleno desenvolvimento.

\section{ASPREVISÕES LEGAISDE COMBATE AOBULLYING ESCOLAR}

A prática do bullying nas escolas não passa impune diante do ordenamento jurídico nacional, acarretando uma série de sanções para seus autores, ou seus responsáveis legais, bem como para a instituição de ensino, caso se mostre omissa no enfrentamento desse problema.

Calhau ${ }^{23}$ aponta: 
Além da Constituição Federal, o Código Civil, Código Penal, Código do Consumidor, entre outras leis, determinam punição (cada um em sua área) de práticas de bullying, sendo que o assunto começou tímido nos tribunais, mas nos últimos cinco anos rompeu os obstáculos iniciais e decisões coibindo o bullying (nos mais diversos ambientes) começam a surgir, sinalizando que o Poder Judiciário não irá tolerar tais condutas, punindo, assim, os responsáveis. [...] Podendo gerar sanções administrativas, trabalhistas, civis ou criminais, dependendo do grau e extensão dos danos causados às vítimas.

Desse modo, o sistema legal brasileiro possui meios para prevenir e, se for o caso, responsabilizar os praticantes dessa forma de violência, com inúmeros mecanismos, a depender da natureza das agressões sofridas pelas vítimas e do ambiente em que são praticadas, como veremos adiante.

\section{O ESTATUTO DA CRIANÇA E DO ADOLESCENTE}

O Estatuto da Criança e do Adolescente - Lei n 8.060/1990 - na esteira da Constituição de 1988, delimitou as diretrizes da proteção integral necessárias, na medida em que ratificou a condição das crianças e dos adolescentes como sujeitos de direitos.

Ressalte-se que, nos termos do Estatuto da Criança e do Adolescente, ${ }^{24}$ " [...] considera-se criança, para os efeitos desta Lei, a pessoa até 12 (doze) anos de idade incompletos, e adolescente aquela entre 12 (doze) e 18 (dezoito) anos de idade".

A fim de proteger crianças e adolescentes contra atos que maculem sua saúde física ou psíquica, o Estatuto da Criança e do Adolescente determina:

Art. 3. ${ }^{\circ}$ A criança e o adolescente gozam de todos os direitos fundamentais inerentes à pessoa humana, sem prejuízo da proteção integral de que trata esta Lei, assegurando-se-lhes, por lei ou por outros meios, todas as oportunidades e facilidades, a fim de lhes facultar o desenvolvimento físico, mental, moral, espiritual e social, em condições de liberdade e de dignidade. ${ }^{25}$

Ora, Elias ${ }^{26}$ oportunamente salienta: 
$\mathrm{O}$ art. $3^{\circ}$ do ECA preceitua que a criança e o adolescente gozam de todos os direitos fundamentais inerentes à pessoa humana, sem prejuízo da proteção integral. Não poderia ser diferente, uma vez que o art. $5^{\circ}$ da Constituição atesta que 'todos são iguais perante a lei, sem distinção de qualquer natureza', e, por conseqüência, são-lhes garantidos todos os direitos [...]. Acrescenta, ainda, o art. $3^{\circ}$ do ECA, que aos menores são asseguradas facilidades e oportunidades, as quais lhes propiciem o desenvolvimento físico, mental, moral, espiritual e social. Isso em condições de liberdade e dignidade.

Nesse diapasão, o Estatuto da Criança e do Adolescente ${ }^{27}$ reconhece que crianças e adolescentes estão em "condição peculiar" por serem "pessoas em desenvolvimento" (art. $6^{\circ}$ ) e, por conseguinte, necessitam de proteção integral.

À luz das disposições do art. 227 da Constituição Federal de 1988, o Estatuto da Criança e do Adolescente estabelece: “Art. $5^{\circ}$ Nenhuma criança ou adolescente será objeto de qualquer forma de negligência, discriminação, exploração, violência, crueldade e opressão, punido na forma da lei qualquer atentado, por ação ou omissão, aos seus direitos fundamentais". ${ }^{28}$

Dessa feita, com o advento do Estatuto da Criança e do Adolescente materializando, principalmente, o art. 227 da Carta Magna, ampliaram-se os desafios trazidos pela doutrina da proteção integral e pelo princípio da prioridade absoluta, conforme se observa em seu art. $4^{\circ}$, in verbis:

Art. $4^{\circ}$ É dever da família, da comunidade, da sociedade em geral e do poder público assegurar, com absoluta prioridade, a efetivação dos direitos referentes à vida, à saúde, à alimentação, à educação, ao esporte, ao lazer, à profissionalização, à cultura, à dignidade, ao respeito, à liberdade e à convivência familiar e comunitária.

Parágrafo único. A garantia de prioridade compreende:

a) primazia de receber proteção e socorro em quaisquer circunstâncias;

b) precedência de atendimento nos serviços públicos ou de relevância pública;

c) preferência na formulação e na execução das políticas sociais públicas; 
d) destinação privilegiada de recursos públicos nas áreas relacionadas com a proteção à infância e à juventude. ${ }^{29}$

Nesse norte, quaisquer atos que causem prejuízos ou que afetem o desenvolvimento físico, psíquico, moral e/ ou social da criança ou do adolescente, bem como agrida a sua dignidade, constituem uma afronta às disposições contidas no Estatuto da Criança e do Adolescente. Tal diploma legal também atesta que:

Art. 15. A criança e o adolescente têm direito à liberdade, ao respeito e à dignidade como pessoas humanas em processo de desenvolvimento e como sujeitos de direitos civis, humanos e sociais garantidos na Instituição e nas leis.

Art. 17. O direito ao respeito consiste na inviolabilidade da integridade física, psíquica e moral da criança e do adolescente, abrangendo a preservação da imagem, da identidade, da autonomia, dos valores, idéias e crenças, dos espaços e objetos pessoais. ${ }^{30}$

Diante da análise dos dispositivos constitucionais contidos nos artigos do Estatuto da Criança e do Adolescente supracitados, torna-se evidente que, ao praticar o bullying, o agressor está violando direitos da vítima, e isso se dá porque o bullying infringe, no mínimo, a imagem, a intimidade e a honra do ofendido. Em casos mais graves, atinge também sua integridade física, o que faz dessa prática um ato ilícito, que merece reprimenda, gerando responsabilidade civil e/ou criminal para seus praticantes ou responsáveis.

\section{RESPONSABILIDADE CIVIL E PENAL COMO FOR- MA DE REPRIMIR O BULLYING}

Diante da reiteração da prática de bullying e da intensificação de sua incidência na sociedade atual, faz-se necessária a análise sobre como proceder quando caracterizado tal ato ilícito, sobretudo como reprimi-lo.

Nascimento e Alkimin, ${ }^{31}$ dissertando sobre a violência e a responsabilidade jurídica, afirmam que: 
O bullying como comportamento ilícito e antijurídico gera dano, ou seja, lesa, causa prejuízos à vítima da agressão, cujo prejuízo ou dano, via de regra, é moral ou extrapatrimonial porque fere a dignidade e personalidade da vítima - lesão à integridade física ou moral/psíquica - pois causa dor sentimental, tristeza, angústia, revolta, enfim, sofrimento no foro íntimo da vítima, não sendo possível aferir de forma certa e determinada o valor do prejuízo moral/psíquico; além do dano material que se caracteriza como sendo aquele que é matematicamente aferível, pois lesa patrimônio da vítima. Qualquer que seja a natureza do dano (moral ou patrimonial) traz a correlata obrigação de reparar o mal causado.

Com base no exposto, tem-se que a prática de bullying configura a ocorrência de atos ilícitos, uma vez que não estão autorizados pelo ordenamento jurídico brasileiro e desrespeitam princípios constitucionais, porque ferem a dignidade e personalidade dos ofendidos, o que gera o dever de reparação do mal sofrido.

De acordo com a lei brasileira, aquele que, por ato ilícito, causar dano a outrem fica obrigado a repará-lo. Haverá obrigação de reparar o dano, independentemente de culpa, nos casos especificados em lei, ou quando a atividade normalmente desenvolvida pelo autor do dano implicar, por sua natureza, risco para os direitos de outrem.

Assim, pode-se considerar a fonte geradora da responsabilidade civil o interesse em restabelecer o equilíbrio violado pelo dano. No entanto, a fim de aplicar o instituto da responsabilidade civil como forma de reprimir o bullying, pressuposto essencial é definir o que é o dano e dissecar os elementos com ele correlacionados.

\section{DEVER DE INDENIZAR E DANO MATERIAL E MO-} RAL EM DECORRÊNCIA DE ATOS DE BULLYING

A própria doutrina descreve o dano como sendo um "[...] fato jurídico gerador da responsabilidade civil, em virtude do qual o ordenamento atribui ao ofendido o direito de exigir a reparação, e ao ofensor a obrigação de repará-lo" ${ }^{32}$

Dessa forma, o dano consiste em um dos pressupostos da responsabilidade civil, uma vez que, para que haja ação de indenização, é requerida a existência de um prejuízo, algo que se procura reparar. ${ }^{33}$ 
Assim, o dano é um prejuízo, uma lesão, que uma pessoa sofre contra sua vontade, devido a determinado evento, afetando qualquer bem ou interesse jurídico, seja patrimonial, seja moral.

Essa lesão não pode ser hipotética, pois, para caracterizar o dano, deve ser real e efetiva, constatando sua ocorrência pelos acontecimentos ou pela repercussão sobre a pessoa ou o patrimônio desta. ${ }^{34}$

Importantes são as palavras de Cavalieri Filho ${ }^{35}$ que afirma:

O dano é, sem dúvida, o grande vilão da responsabilidade civil. Não haveria que se falar em indenização, nem em ressarcimento, se não houvesse dano. Pode haver responsabilidade sem culpa, mas não pode responsabilidade sem dano. Na responsabilidade objetiva, qualquer que seja a modalidade do risco que lhe sirva de fundamento - risco profissional, risco proveito, risco criado etc. -, o dano constitui o seu elemento preponderante. Tanto é assim que, sem dano, não haverá o que reparar, ainda que a conduta tenha sido culposa ou até dolosa.

Para arrematar essas considerações sobre o dano, é importante a análise de sua classificação. A priori, a doutrina classifica o dano em patrimonial (material) ou extrapatrimonial (moral).

Nas palavras de Cavalieri Filho: ${ }^{36}$

O dano patrimonial, como o próprio nome diz, também chamado de dano material, atinge os bens integrantes do patrimônio da vítima, entendendo-se como tal o conjunto de relações jurídicas de uma pessoa apreciáveis em dinheiro. Nem sempre, todavia, o dano patrimonial resulta da lesão de bens ou interesses patrimoniais [...]. A violação de bens personalíssimos, como o bom nome, a reputação, a saúde, a imagem e a própria honra, pode refletir no patrimônio da vítima, gerando perda de receitas ou realização de despesas - o médico difamado perde a sua clientela -, o que para alguns autores configura o dano patrimonial indireto.

Portanto, depreende-se que o dano patrimonial (ou material) pode advir da perda de um bem incorpóreo. Uma das condições para a caracterização do dano patrimonial é que a perda seja avaliável, aferida pela diferença entre o valor atual do patrimônio da vítima e aquele que teria, no mesmo momento, se não houvesse a lesão, configurando-se numa situação bem diversa do dano moral. 
Por sua vez, o dano moral vem a ser qualquer lesão de interesses não patrimoniais de pessoa física ou jurídica, provocada pelo fato lesivo. $^{37}$

Assim, conforme a análise dos conceitos acima expostos, pode-se concluir que o dano patrimonial se distingue do moral pela possibilidade de aquele ser indenizado pelo equivalente em dinheiro, situação que não ocorre com o dano moral, uma vez que neste não é possível aferir de forma certa e determinada o valor do prejuízo moral/psíquico sofrido pela vítima.

Por conseguinte, faz-se mister destacar que a responsabilidade civil abrange também a ocorrência de um ato ilícito, como bem destaca o Código Civil em seu art. 186: " [...] aquele que, por ação ou omissão voluntária, negligência ou imprudência, violar direito e causar dano a outrem, ainda que exclusivamente moral, comete ato ilícito" ${ }^{38}$

O diploma legal acima transcrito estabelece o ilícito como fonte de obrigação de indenizar os danos causados à vítima, sendo reforçado pelo art. 927 do mesmo instrumento codificante, que reza: "[...] aquele que, por ato ilícito (arts. 186 e 187), causar dano a outrem, fica obrigado a repará-lo". ${ }^{39}$

Assim, conforme o disposto no art. 186, do Código Civil, a responsabilidade somente é excluída se o ato do agente não for voluntário, em que o evento danoso é proveniente de caso fortuito ou de força maior. Nas demais hipóteses, havendo dano a outrem, subsiste a obrigação da reparação.

Imperioso destacar que, além do dano e da existência de um ato ilícito, para que surja a obrigação de indenizar, é necessária a existência de uma relação de causalidade entre o prejuízo e a conduta do agente lesante, pois, se o dano for originário da negligência da própria vítima, não há a obrigatoriedade de ressarcimento. ${ }^{40}$

Feitas as devidas considerações, retomando a discussão sobre o bullying como um comportamento ilícito e antijurídico gerador de dano, pode-se afirmar que qualquer que seja a natureza do dano sofrido pela vítima, existe sempre a obrigação de reparar o mal causado.

Dessa feita, aduzem Nascimento e Alkimin ${ }^{41}$ que “[...] a responsabilidade jurídica nasce com o dever de indenizar, sendo facultado à 
vítima do bullying exigir esse dever de reparação dos prejuízos experimentados através do acionamento do Poder Judiciário por meio da Ação de Indenização".

Ao analisar as consequências e os efeitos da prática do bullying, Nascimento e Alkimin ${ }^{42}$ explicam:

A conseqüência imediata do bullying é o dano moral, ou seja, aquele que se traduz em sofrimento humano em razão da lesão à dignidade e personalidade, cujo sofrimento não tem nenhuma ligação com perda de patrimônio ou perda pecuniária, mas está relacionado à reputação da vítima, à honra, à sua imagem e autoridade, ao pudor e amor-próprio, à saúde e integridade física e psíquica, bens jurídicos que não possuem valor de mercado, todavia, valor subjetivo para cada indivíduo, posto que relacionados a atributos pessoais e individuais com projeção na sociedade.

Ora, a dignidade e a personalidade da vítima do bullying não têm preço e jamais o prejuízo/dano por ela sofrido será compensado com o pagamento de certa quantia em dinheiro. Nesses casos, diferentemente do que ocorre na reparação de um dano material/patrimonial, a indenização não se destina a ressarcir os prejuízos morais e psíquicos sofridos pela vítima, visa, na realidade, a compensar toda dor, sofrimento íntimo e angústia, que atingem as referidas vítimas da violência. Igualmente, visa a proporcionar ao agressor (autor da violência) uma perda patrimonial, que se configura como uma forma de punição e tem o objetivo explícito de desestimulá-lo a praticar novamente a conduta ilícita e antijurídica, geradora da ação de indenização.

Examinando a responsabilidade jurídica dos pais em relação às ações de bullying praticadas pelos filhos, Nascimento e Alkimin esclarecem: ${ }^{43}$

No caso do bullying cometido por alunos menores de idade (menores de 18 anos) os pais respondem pelo ato ilícito cometido pelo filho, devendo-se considerar os seguintes aspectos:

a) a lei considera o menor de 18 anos de idade incapaz de reger os atos da vida civil e de assumir obrigações e responsabilidades, sendo que o legislador dividiu a incapacidade em absoluta (menores de 16 anos de idade) e relativa (dos 16 aos 18 anos de idade); 
b) como são incapazes de assumir obrigações, em especial, o pagamento de indenização pelo ato ilícito (bullying), os pais, responsáveis pela criação, educação e guarda dos filhos, é que deverão responder.

Dessa maneira, quando se trata de agressores menores de 18 anos, a responsabilidade recai sobre os pais ou responsáveis, porque a estes cabe a obrigação de incutir princípios morais rígidos na formação de seus filhos, tendo também o dever de ensiná-los a respeitar e considerar seus semelhantes, prestando orientação para que tais filhos estabeleçam uma boa convivência social, enxergando a escola como um ambiente de construção da civilidade e cidadania, onde se deve conviver harmonicamente com todas as diferenças, sejam elas raciais, religiosas, culturais ou econômicas.

Ao estabelecer a responsabilidade que recai sobre os pais/responsáveis, o Código Civil em vigor preleciona:

Art. 932. São também responsáveis pela reparação civil:

I - os pais, pelos filhos menores que estiverem sob sua autoridade e em sua companhia;

II - o tutor e o curador, pelos pupilos e curatelados, que se acharem nas mesmas condições;

Art. 933. As pessoas indicadas nos incisos I a V do artigo antecedente, ainda que não haja culpa de sua parte, responderão pelos atos praticados pelos terceiros ali referidos. ${ }^{44}$

Diante do exposto, observa-se que é dever dos pais e responsáveis exercer sobre as crianças e adolescentes uma vigilância contínua, evitando assim que eles causem prejuízos a outrem. Ressalte-se, portanto, que a responsabilidade jurídica dos pais independe se os filhos agiram com culpa ou não, pois o legislador considera, no caso de ato ilícito, como o bullying, por exemplo, cometido por menor, a culpa presumida (responsabilidade sem culpa) por parte dos pais, não podendo invocar o argumento de que não tinham conhecimento ou de que não havia obediência por parte dos filhos. Trata-se, como mencionado, de responsabilidade sem culpa, que decorre de imperativo legal.

\section{Esclarecem ainda Nascimento e Alkimin: ${ }^{45}$}


Em termos de responsabilidade jurídica dos pais no caso de bullying perpetrado pelo filho, há de se considerar duas hipóteses:

a) ao filho menor de idade, com idade inferior a 16 anos de idade, em razão de sua incapacidade absoluta não recairá o dever de indenizar e sim aos pais, detentores do poder familiar e do dever de guarda e vigilância;

b) o filho maior de 16 e menor de 18 anos de idade que pratica o bullying, como é relativamente capaz, responderá solidariamente com os pais em eventual ação de indenização pela reparação dos danos causados pela conduta antijurídica, ou seja, tanto o menor autor do bullying como seus pais poderão ser acionados judicialmente.

Da análise do acima transcrito, é oportuno ressaltar as disposições contidas no art. 928, do Código Civil, que determina que, tanto no caso de incapacidade absoluta como relativa, o pagamento da indenização será deduzido do patrimônio do menor, caso seus pais não possuam os recursos suficientes para quitar a indenização estabelecida pelo juiz. Contudo, essa indenização "[...] não terá lugar se privar do necessário o incapaz ou as pessoas que dele dependem". ${ }^{46}$

Segundo Lélio Braga Calhau, ${ }^{47} \mathrm{O}$ quantum da indenização nos casos de bullying "[...] será decido pelo Poder Judiciário, que o fará baseado unicamente nas provas produzidas pelas partes em juízo".

De outra banda, a obrigação de indenizar a vítima de bullying pode ir além do dever do agressor ou de seus pais/responsáveis. Essa obrigação também pode ser estendida às instituições de ensino.

Trata-se de escolas, sistema de educação, profissionais que tenham em vista os direitos de crianças e adolescentes. Com respeito à violação desses direitos, Ferreira ${ }^{48}$ lembra que:

O Estatuto estabeleceu, no artigo 70, a obrigatoriedade a todos de prevenir a ocorrência de ameaça ou violação dos direitos da criança e do adolescente. Dentro dessa lógica, assumem o professor e os dirigentes dos estabelecimentos de ensino a obrigação de prevenir eventual lesão ou violação dos direitos fundamentais dos alunos, cumprindo o que foi estabelecido na lei quanto à comunicação ao Conselho Tutelar das questões relativas a maus-tratos [...] faltas injustificadas, evasão escolar e elevados níveis de repetência [...]. 
Ora, é dever da escola, seja ela pública, seja privada, “[...] zelar pela integridade física e psíquica tanto de seus alunos como de seus professores, [além do mais, ela] tem o dever de vigiar, fiscalizar e empreender medidas que visem prevenir e evitar" a prática do bullying em seu meio. ${ }^{49}$

Oportuno ressaltar que é certo que o bullying cometido na escola caracterizará violação ao dever de fiscalização, vigilância e eleição em relação aos seus discentes, recaindo a responsabilidade jurídica sobre o Estado, no caso de escola pública, ou sobre a instituição de ensino, no caso da escola privada.

Nesse sentido, Nascimento e Alkimin ${ }^{50}$ informam:

O Estado responde por danos causados a terceiros por ato de seus agentes (funcionários ou servidores), cuja responsabilidade jurídica é denomina de responsabilidade civil objetiva, ou seja, basta a conduta ilícita (bullying) por parte de seus educandos e o dano (físico e/ou psíquico) causado a um professor, a outros alunos ou a terceiros, cuja teoria tem como supedâneo o risco de dano que a atividade pública pode gerar para os beneficiários da prestação do serviço público. Ao lado da responsabilidade jurídica do Estado está a responsabilidade jurídica das instituições de ensino privadas, as quais, tal como as escolas públicas, devem zelar pela integridade física e psíquica dos discentes e docentes, tanto que o legislador civil dispôs que as instituições de ensino respondem civilmente, ou seja, deverão pagar a indenização e, conseqüentemente, reparar o dano causado por seus educandos, e certo que de forma objetiva, ou seja, não se pauta a responsabilidade do Estado em eventual ato culposo (negligência, imprudência ou imperícia) ou doloso (intencional) de seus agentes públicos, pois mesmo que não haja culpa da parte dos mesmos, o Estado responderá (arts. 932, IV e 933 do Código Civil).

Portanto, com base no exposto, é certo que a escola tem responsabilidade jurídica no caso do bullying praticado em seu interior. Se o agressor for menor de idade, os pais poderão responder solidariamente com a instituição de ensino. E, quando o ato qualificado como bullying for cometido por aluno maior de 18 anos de idade, este responderá por seu ato. Contudo, a responsabilidade solidária da instituição de ensino ou do Estado é mantida, observando o que dispõe o $\S$ único do art. 942 do Código Civil, combinado com o art. 932, IV. 
Dessa feita, claramente se denota que os atos ilícitos caracterizadores do bullying, em todas as suas formas, configuram objeto de reparação no campo cível. No entanto, os efeitos jurídicos produzidos pela prática do bullying vão mais além da responsabilidade civil, já que o bullying é uma prática que também se configura como crime, indo de encontro às disposições contidas no Código Penal.

\section{RESPONSABILIDADE POR ATOS DE BULLYING NA ESFERA PENAL}

Após os inúmeros debates e discussões que trazem como tema a questão do bullying, sua prática passou a deixar de ser confundida como simples brincadeiras de crianças e adolescentes ou entre colegas de trabalho. Consoante análise já feita com o advento da Constituição Federal de 1988, a sociedade brasileira passou a contar com um dispositivo que determina que os danos matérias ou morais sejam passíveis de indenização. A referida garantia encontra-se expressa no art. $5^{\circ}, \mathrm{X}$, do texto constitucional em vigor, aduzindo que: "[...] são invioláveis a intimidade, a vida privada, a honra e a imagem das pessoas, assegurando o direito a indenização pelo dano material ou moral decorrente de sua violação".

Os casos nos quais a honra e a imagem da pessoa são danificadas estão descritos no Código Penal, quando trata dos crimes contra a honra. ${ }^{51}$

O bullying consiste em uma espécie de ofensa perpetrada pelo agressor contra a vítima, o que atinge efetivamente a dignidade da pessoa humana, sua integridade física e/ ou moral. Por isso, o combate a essa espécie de violência, abrangendo suas várias formas, passou a representar uma das maneiras de defender as vítimas dessa ação ilícita.

Ainda se carece de uma legislação específica sobre o bullying, porém tal fato não impede uma resposta judicial às agressões sofridas pelas vítimas. No âmbito penal, o bullying pode ser tipificado por condutas como lesão corporal, injúria, calúnia, constrangimento ilegal, difamação, ameaça, maus-tratos e dano. São crimes claramente definidos no Código Penal, possuindo os tratamentos apresentados no quadro abaixo. 
Identificação e proibição do bullying escolar no ordenamento jurídico brasileiro: perspectiva de violação dos direitos humanos de crianças e adolescentes

\section{QUADRO 1 - CRIMES DEFINIDOS COMO BULLYING}

\begin{tabular}{|c|c|c|}
\hline CRIME & ENQUADRAMENTO PENAL & PENA \\
\hline Lesão corporal & $\begin{array}{l}\text { Art. } 129 . \text { Ofender a integridade } \\
\text { corporal ou a saúde de outrem }\end{array}$ & $\begin{array}{l}\text { Pena - detenção, de } 03 \text { (três) meses a } \\
01 \text { (um) ano }\end{array}$ \\
\hline Maus-tratos & $\begin{array}{l}\text { Art. 136. Expor a perigo a vida ou } \\
\text { a saúde de pessoa sob sua autori- } \\
\text { dade, guarda ou vigilância, para } \\
\text { fim de educação, ensino, trata- } \\
\text { mento ou custódia, quer privan- } \\
\text { do-a de alimentação ou cuidados } \\
\text { indispensáveis, quer sujeitando a } \\
\text { trabalho excessivo ou inadequa- } \\
\text { do, quer abusando de meios de } \\
\text { correção ou disciplina }\end{array}$ & $\begin{array}{l}\text { Pena - detenção, de } 02 \text { (dois) meses a } \\
01 \text { (um) ano, ou multa } \\
\S 1^{\circ} \text { - Se do fato resulta lesão corporal } \\
\text { de natureza grave: } \\
\text { Pena - reclusão, de } 01 \text { (um) a } 04 \text { (qua- } \\
\text { tro) anos } \\
\S 2^{\circ} \text { - Se resulta a morte: } \\
\text { Pena - reclusão, de } 04 \text { (quatro) a } 12 \\
\text { (doze) anos } \\
\S 3^{\circ} \text { - Aumenta-se a pena de um terço, } \\
\text { se o crime é praticado contra pessoa } \\
\text { menor de } 14 \text { (catorze) anos. (Acres- } \\
\left.\text { centado pela Lei }{ }^{\circ} 8.069 / 1990\right)\end{array}$ \\
\hline Calúnia & $\begin{array}{l}\text { Art. 138. Caluniar alguém, im- } \\
\text { putando-lhe falsamente fato de- } \\
\text { finido como crime }\end{array}$ & $\begin{array}{l}\text { Pena - detenção, de } 06 \text { (seis) meses a } \\
02 \text { (dois) anos e multa } \\
\S 1^{\circ} \text { - Na mesma pena incorre quem, } \\
\text { sabendo falsa a imputação, a propa- } \\
\text { ga ou divulga } \\
\S 2^{\circ} \text { - É punível a calúnia contra os } \\
\text { mortos }\end{array}$ \\
\hline Difamação & $\begin{array}{l}\text { Art. } 139 . \text { Difamar alguém, im- } \\
\text { putando-lhe fato ofensivo à sua } \\
\text { reputação }\end{array}$ & $\begin{array}{l}\text { Pena - detenção, de } 03 \text { (três) meses a } \\
01 \text { (um) ano e multa }\end{array}$ \\
\hline Injúria & $\begin{array}{l}\text { Art. 140. Injuriar alguém, ofen- } \\
\text { dendo-lhe a dignidade ou o de- } \\
\text { coro }\end{array}$ & $\begin{array}{l}\text { Pena - detenção, de } 01 \text { (um) a } 06 \\
\text { (seis) meses ou multa }\end{array}$ \\
\hline $\begin{array}{l}\text { Constrangimento } \\
\text { ilegal }\end{array}$ & $\begin{array}{l}\text { Art. 146. Constranger alguém, } \\
\text { mediante violência ou grave ame- } \\
\text { aça, ou depois de lhe haver redu- } \\
\text { zido, por qualquer outro meio, a } \\
\text { capacidade de resistência, a não } \\
\text { fazer o que a lei permite, ou a fa- } \\
\text { zer o que ela não manda }\end{array}$ & $\begin{array}{l}\text { Pena - detenção, de } 03 \text { (três) meses a } \\
01 \text { (um) ano ou multa }\end{array}$ \\
\hline Ameaça & $\begin{array}{l}\text { Art. 147. Ameaçar alguém, por } \\
\text { palavra, escrito ou gesto, ou } \\
\text { qualquer outro meio simbólico, } \\
\text { de causar-lhe mal injusto e grave }\end{array}$ & $\begin{array}{l}\text { Pena - detenção, de } 01 \text { (um) a } 06 \\
\text { (seis) meses ou multa. } \\
\S \text { único - Somente se procede me- } \\
\text { diante representação }\end{array}$ \\
\hline Dano & $\begin{array}{l}\text { Art. } 163 \text {. Destruir, inutilizar ou } \\
\text { deteriorar coisa alheia }\end{array}$ & $\begin{array}{l}\text { Pena - detenção, de } 01 \text { (um) a } 06 \\
\text { (seis) meses ou multa }\end{array}$ \\
\hline
\end{tabular}

FONTE: Brasil (2008), adaptado. 
Desse modo, ao tratar do bullying na esfera penal, o Judiciário avalia a ação em trâmite e promove o enquadramento penal, observando se a agressão sofrida pela vítima se configura como uma ameaça, uma calúnia, um constrangimento ilegal, um dano (material ou moral), uma difamação, injúria, lesão corporal ou maus-tratos.

Importante ressaltar que já tramita na Câmara Federal um Projeto de Lei $\mathrm{n}^{\circ}$ 6.935/10, apresentado pelo deputado Fábio Faria, que pretende promover significativas mudanças no Código Penal, incluindo, no capítulo dos crimes contra a honra, o crime de intimidação. Por fim, inúmeros outros projetos de lei que tratam da prevenção e repressão do bullying estão em discussão nas Casas Legislativas municipais e estaduais em todo o País.

\section{CONSIDERAÇÕES FINAIS}

O bullying é uma prática que cresce a cada dia, de forma silenciosa e assustadora, merecendo a atenção da sociedade em geral, tendo em vista a repercussão e o medo que causa no ambiente social, sobretudo nas crianças e adolescentes, principais vítimas de sua prática. É um fator de violência que configura atos que evidenciam a exploração dos mais fracos ou dos diferentes e que tem como motor a intolerância com o próximo.

Reconhecido como um fenômeno de grande preocupação social, o bullying passou a ganhar contornos diferenciados ao longo do tempo e grau de violência preocupante na sociedade moderna, tendo feito um número incalculável de vítimas, deixando não somente traumas e danos, mas, em casos mais graves, produzindo mortes.

Como esse fenômeno vem assumindo dimensões mais amplas no ambiente escolar, onde não raro as vítimas sofrem em silêncio durante anos, por medo ou vergonha, é de extrema importância que se estabeleçam ações visando ao desenvolvimento de programas preventivos eficazes, aptos a coibir os atos promovidos pelos agressores nesse contexto, reduzindo, assim, as consequências e o número de vítimas.

Por meio da análise do material bibliográfico utilizado para fundamentar o presente artigo, constatou-se que o bullying ainda não é 
um tema devidamente enfrentado e difundido no meio jurídico, sendo, portanto, atribuído mais ao âmbito escolar.

No entanto, é imprescindível esclarecer que o fenômeno do bullying possui vários pontos que estão diametralmente correlacionados com o Direito. Entre esses pontos, pode-se citar a discriminação, intimidação, além do assédio físico e/ ou moral. Dessa forma, o bullying não está afastado dos aspectos jurídicos que gravitam ao seu redor.

Na presente pesquisa, também se constatou que a legislação existente no Brasil, especificadamente o Estatuto da Criança e do Adolescente, está mais inclinada para o combate das manifestações do bullying no ambiente escolar e que ainda não existe uma norma estabelecendo a tipificação penal dessa prática, apesar dos inúmeros projetos de leis que tramitam nas Casas Legislativas municipais e estaduais em todo o País nesse sentido.

Dessa maneira, no âmbito jurídico, ainda não há como se falar em criminalização do bullying. No entanto, deve-se lembrar que as ações que podem configurar essa prática ensejam responsabilidade no campo civil e penal.

Assim, com base no material analisado, pode-se concluir que, em matéria de proteção jurídica, o bullying é uma afronta direta à dignidade e aos direitos da personalidade de suas vítimas, afetando sua integridade psíquica e/ou física. Assim, com base no Código Civil, mais especificamente em seus arts. 186 e 927, gera para o agressor, ou para seu responsável, quando aquele for menor de idade, a obrigação de reparar os danos moral e material causados pelo cometimento de um ato ilícito.

Por outro lado, se as ações configuradas como bullying (ameaças, constrangimento ilegal, difamação, entre outras) forem praticadas por maior de idade, será aplicada a lei penal, que define tais ações como crime, não se tratando essencialmente de bullying.

Por tudo o que foi exposto, conclui-se que a sociedade precisa romper com a cultura do silêncio, do preconceito e da discriminação, tomando iniciativas que visem a cessar essa forma de violência, que se caracteriza como uma violação direta dos direitos humanos. 
Para se construir essa postura social, é preciso fomentar uma atitude de cooperação, reciprocidade e respeito mútuo, chamando a atenção do grande público para a importância de prevenir e combater o bullying, convocando a participação de todos para o trabalho de incentivo a uma cultura de paz, estabelecendo uma luta contínua pela proteção da dignidade humana.

Portanto, na busca de mudar a atitude omissa da maioria da população em frente às práticas de bullying, é necessário que a reflexão sobre esse tema envolva educadores, familiares, profissionais das mais diversas áreas do conhecimento e a sociedade em geral, a fim de desenvolverem a real consciência da importância de um trabalho educativo e preventivo direcionado principalmente às crianças e adolescentes, a fim de que sejam educados para a Cidadania, para a Democracia e para o respeito aos Direitos Humanos.

\section{NOTAS}

1 ESCOREL, Soraya Soares da Nóbrega. Projeto bullying não é brincadeira: prevenção à violência física, psicológica e sexual na escola. João Pessoa: Ministério Público do Estado da Paraíba, 2011. p. 202. (Manual de atuação funcional da criança e do adolescente).

2 FANTE, Cleo; PEDRA, José Augusto. Bullying escolar: perguntas e respostas. Porto Alegre: Artmed, 2008. p. 34.

3 Middelton-Moz, apud ESCOREL, Soraya Soares da Nóbrega. Projeto bullying não é brincadeira: prevenção à violência física, psicológica e sexual na escola. João Pessoa: Ministério Público do Estado da Paraíba, 2011. p. 204. (Manual de atuação funcional da criança e do adolescente).

4 CALHAU, Lélio Braga. Bullying: o que você precisa saber. Rio de Janeiro: Impetus, 2010.

5 FANTE, Cleo. Fenômeno bullying: como prevenir a violência nas escolas e educar para a paz. Campinas: Venus, 2005. p. 73.

6 FANTE, Cleo; PEDRA, José Augusto, op. cit., p. 45

7 SILVA, Ana Beatriz Barbosa. Bullying: mentes perigosas nas escolas. Rio de Janeiro: Objetiva, 2010. p. 40.

8 Ibid., p. 42.

9 SILVA, op. cit., p. 45-46

10 ABRAMOVAY, Miriam; CALAF, Priscila. Revista Jurídica Consulex, ano XIV, n. 325, p. 34-35, ago. 2010.

11 FANTE, Cleo. Bullying no ambiente escolar. Revista Jurídica Consulex, ano XIV, n. 325, p. 36, ago. 2010.

12 LOPES NETO, Aramins. Bullying: comportamento agressivo entre estudantes. Jornal de Pediatria, Rio de Janeiro, 81(5 Supl):S164-S172, 2005.

13 ESCOREL, op. cit. p. 214.

14 SILVA, op. cit., p. 162.

15 LOPES NETO, op. cit.

16 FANTE, 2010, op. cit., p. 73.

17 BRASIL. Constituição (1988). Constituição [da] República Federativa do Brasil. Brasília: Senado Federal, 2009. p. 15-17. 
18 BASTOS, Celso Ribeiro. Curso de direito constitucional. 22. ed. São Paulo: Saraiva, 2001. p. 158.

19 NASCIMENTO, Grasiele Augusta Ferreira; ALKIMIN, Maria Aparecida. Violência na escola: o bullying na relação aluno-professor e a responsabilidade jurídica. In: ENCONTRO NACIONAL DO CONPEDI, 19., 2010, Fortaleza - CE, 9 A 12 de junho de 2010. In: Anais... Fortaleza: Conpedi, 2010. Disponível em: <http:/ / www.conpedi.org.br/manaus/arquivos/ anais/fortaleza/3776.pdf>. Acesso em: 21 ago 2011. p. 2815.

20 BRASIL, op. cit., p. 126-127.

21 FERREIRA, Luiz Antonio Miguel. O Estatuto da Criança e do Adolescente e o professor: reflexos na sua formação e atuação. São Paulo: Cortez, 2008. p. 40.

22 MARTINS, Daniele Comin. Estatuto da Criança e do Adolescente \& política de atendimento. 6. tir. Curitiba: Juruá, 2008. p. 47.

23 CALHAU, op. cit., p. 15.

24 BRASIL. Ministério da Saúde. Estatuto da Criança e do Adolescente. Série E, Legislação de saúde. 3. ed. Brasília: Ministério da Saúde, 2006. p. 9.

25 Idem.

26 ELIAS, Roberto João. Direitos fundamentais da criança e do adolescente. São Paulo: Saraiva, 2005. p. 3

27 MARTINS, op. cit., p. 10.

28 BRASIL, op. cit., p. 10.

29 Idem.

30 BRASIL, op. cit., p. 11

31 NASCIMENTO; ALKIMIN, op. cit., p. 2816.

32 BAPTISTA, Silvio Neves. Teoria geral do dano: de acordo com o novo código civil brasileiro. São Paulo: Atlas, 2003. p. 43.

33 DINIZ, Maria Helena. Curso de direito civil brasileiro: responsabilidade civil. São Paulo: Saraiva, 2007. v. 7. p. 59.

34 Ibid., p. 63-64.

35 CAVALIERI FILHO, Sérgio. Programa de responsabilidade civil. 5. ed. São Paulo: Malheiros, 2004. p. 41.

36 Ibid., p. 89.

37 DINIZ, op. cit., p. 88.

38 BRASIL. Código Civil Brasileiro. Brasília: Senado Federal, 2008. p. 84.

39 Ibid., p. 174.

40 DINIZ, op. cit. , p. 69

41 NASCIMENTO; ALKIMIN, op. cit., p. 2817.

42 NASCIMENTO; ALKIMIN, op. cit., p. 2816.

43 NASCIMENTO; ALKIMIN, op. cit., p. 2817.

44 BRASIL, 2008, P. 178-179.

45 Idem.

46 BRASIL, op. cit., p. 178.

47 CALHAU, op. cit., p. 17.

48 FERREIRA, op. cit., p. 59

49 NASCIMENTO; ALKIMIN, op. cit., p. 2818

50 Idem

51 GRECO. R. Curso de direito penal. Parte geral. 9. ed. Rio de Janeiro: Impetus, 2007. 


\section{REFERÊNCIAS}

ABRAMOVAY, Miriam; CALAF, Priscila. Revista Jurídica Consulex, ano XIV, n. 325, ago. 2010.

BAPTISTA, Silvio Neves. Teoria geral do dano: de acordo com o novo código civil brasileiro. São Paulo: Atlas, 2003.

BASTOS, Celso Ribeiro. Curso de direito constitucional. 22. ed. São Paulo: Saraiva, 2001.

BRASIL. Código Civil Brasileiro. Brasília: Senado Federal, 2008. Constituição (1988). Constituição [da] República Federativa do Brasil. Brasília: Senado Federal, 2009.

CALHAU, Lélio Braga. Bullying: o que você precisa saber. Rio de Janeiro: Impetus, 2010.

CAVALIERI FILHO, Sérgio. Programa de responsabilidade civil. 5. ed. São Paulo: Malheiros, 2004.

DINIZ, Maria Helena. Curso de direito civil brasileiro: responsabilidade civil. São Paulo: Saraiva, 2007. v. 7.

ELIAS, Roberto João. Direitos fundamentais da criança e do adolescente. São Paulo: Saraiva, 2005.

ESCOREL, Soraya Soares da Nóbrega. Projeto bullying não é brincadeira: prevenção à violência física, psicológica e sexual na escola. João Pessoa: Ministério Público do Estado da Paraíba, 2011. (Manual de atuação funcional da criança e do adolescente).

FANTE, Cleo. Fenômeno bullying: como prevenir a violência nas escolas e educar para a paz. Campinas: Venus, 2005.

FANTE, Cleo; PEDRA, José Augusto. Bullying escolar: perguntas e respostas. Porto Alegre: Artmed, 2008.

FANTE, Cleo. Bullying no ambiente escolar. Revista Jurídica Consulex, ano XIV, n. 325, $1^{\mathrm{o}}$ ago. 2010. 
FERREIRA, Luiz Antonio Miguel. O Estatuto da Criança e do Adolescente e o professor: reflexos na sua formação e atuação. São Paulo: Cortez, 2008.

GRECO. R. Curso de direito penal. Parte geral. 9. ed. Rio de Janeiro: Impetus, 2007.

LOPES NETO, Aramins. Bullying: comportamento agressivo entre estudantes. Jornal de Pediatria, Rio de Janeiro, n. 81(5 Supl):S164-S172, 2005.

MARTINS, Daniele Comin. Estatuto da criança e do adolescente \& política de atendimento. 6. tir. Curitiba: Juruá, 2008.

Ministério da Saúde. Estatuto da criança e do adolescente. Série E, Legislação de saúde. 3. ed. Brasília: Ministério da Saúde, 2006.

NASCIMENTO, Grasiele Augusta Ferreira; ALKIMIN, Maria Aparecida. Violência na escola: o bullying na relação aluno-professor e a responsabilidade jurídica. In: ENCONTRO NACIONAL DO CONPEDI, 19., 2010, Fortaleza - CE, 9 A 12 de junho de 2010. In: Anais... Fortaleza: Conpedi, 2010. Disponível em: <http:/ / www.conpedi.org.br/manaus/ arquivos/anais/fortaleza/3776.pdf>. Acesso em: 21 ago 2011.

SILVA, Ana Beatriz Barbosa. Bullying: mentes perigosas nas escolas. Rio de Janeiro, Objetiva, 2010.

Artigo recebido em: 24-12-2011

Aprovado em: 17-12-2012 